\section{Delayed onset of extrapyramidal side-effects on combining paroxetine with risperidone}

Sir - We report a case of delayed extrapyramidal side-effects occurring when paroxetine was administered in combination with risperidone. A 45 year old man was admitted with depression and suicidal ideation. He had a previous diagnosis of paranoid schizophrenia. His pharmacological treatment in the past had varied from flupenthixol decanoate $40 \mathrm{mg}$ per month to trifluoperazine $15 \mathrm{mg}$ per day in combination with trimipramine $125 \mathrm{mg}$ daily. Following a further admission he was commenced on haloperidol $1.5 \mathrm{mg}$ and diazepam $5 \mathrm{mg}$ three times per day. Subsequently he was given risperidone which was increased to $6 \mathrm{mg}$ per day. He had no prior history of extrapyramidal side-effects. Following his last admission, he was commenced on paroxetine $20 \mathrm{mg}$ per day and his risperidone was reduced to $4 \mathrm{mg}$ daily. At discharge 18 days later there were no evidence of any side-effects. The patient did not attend for a follow up appointment until 48 days later. He then displayed obvious bucco-facial rigidity as well as involuntary movements of this area. He did not have any other extrapyramidal side-effects. Paroxetine and risperidone were discontinued and he was treated with benzetropine with resolution of the extrapyramidal side-effects. The addition of paroxetine appears to have been the likely causative factor of extrapyramidal side effects in this patient as he had already tolerated a higher dose of risperidone for a year prior to this. This would also suggest that the inhibitory action of paroxetine on the breakdown of risperidone was not precipitating factor. Both drugs are broken down by the same isoenzyme (CYP2D6), of the hepatic cytochrome p450. Compared with other serotonin uptake inhibitors paroxetine is the greatest inhibitor of this isoenzyme. ${ }^{1}$ This suggests that paroxetine alone caused the extrapyramidal side-effects. Previous reports have linked selective serotonin uptake inhibitors (SSRIs) with these effects. ${ }^{2.3}$ So far these have mainly included fluoxetine and fluvoxamine. This case suggests that paroxetine is a causative factor in extrapyramidal side-effects and this action can sometimes be delayed. We feel that it is important to be aware of this side-effect, not only in the initial stages, but continually during the patients treatment .

\section{References}

1. Baumann P, Rochat B. Comparative pharmokinetics of selective serotonin uptake inhibitors: a look behind the mirror. Int Clin Psychopharmacol 1995; 10: 15-21.

2. Arya DK. Extrapyramidal symptoms with selective serotonin uptake inhibitors. Br J Psychiatry 1994; 165: 728-33.

3. AI-Adwani A. Brain damage and tardive dyskinesia. Br J Psychiatry 1995; 167: 410-1.

Barbara Farragher, MB, MRCPsych, Senior Registrar in Psychiatry, Clondalkin Mental Health Service, Unit 1A, The Village Centre, Orchard Road, Clondalkin, Dublin 22, Ireland.

Noel Walsh, FRCPsych, FRCP(C), Professor of Clinical Psychiatry, St Vincent's Hospital, Elm Park, Dublin 4, Ireland.

\section{Capgras syndrome in postpartum depression}

Sir - A case is described which is only the third report of Capgras' syndrome in the puerperium without an organic basis, and the first in which the child is the sole misidentified person. My discussion includes a brief review of the literature.

Introduction: Capgras' syndrome (Lillusion des sosies - the illusion of doubles) was first described in 1923 by Capgras and Reboul-Lachaux ${ }^{1}$ who reported a woman with the delusional belief that some family members had been replaced by identical doubles. According to Enoch and Trethowan ${ }^{2}$ it is the most frequently occurring of the delusional misidentification syndromes but is still extremely rare.

According to Cox, ${ }^{3}$ puerperal psychoses are relatively rare and occur following $0.2 \%$ of live births. They are difficult to classify using ICD- $10^{4}$ as there is no separate category of puerperal psychosis. However, DSM-IV' does offer a 'Postpartum onset specifier" which can be applied to mood disorders or to a brief psychotic disorder.

There are few references in the literature to any of the delusions of misidentification occurring in a puerperal illness. ${ }^{6} \mathrm{We}$ report only the third case of Capgras' syndrome occurring in the puerperium in the absence of an organic lesion, and the first in which the child was the sole misidentified person in this period.

Case Report: $\mathrm{C}$ is a 28 year old married office worker. Her mother has a bipolar mood disorder. Apart from an overdose following elective termination of her one previous pregnancy more than 10 years ago, her history was orherwise unremarkable. She had no previous psychiatric contact.

She was admitted 37 weeks into a planned pregnancy following an overdose. There was a history of several months of low mood, poor self-esteem, poor appetite and early morning wakening. Because of the pregnancy, only as required medication was used. Over the next few days, she became agitated and deluded, telephoning the police to say she had been 'set up'. Labour was induced and she delivered a healthy baby. She continued to be deluded, saying her husband was having an affair and that her baby had been switched with another identical one. She was keen to look after the 'second' baby and at no time did she express any negative feelings toward it. Indeed her plan was to keep both babies when her own was returned.

She was given chlorpromazine, lithium carbonate and fluoxetine (which was stopped because of a skin rash) in addition to electro-convulsive treatment. She gradually improved and was symptom free, with no abnormal thoughts about her baby, when she was discharged at 20 days postpartum.

Discussion: Nilsson and Perris ${ }^{7}$ and Foerst ${ }^{8}$ reported cases of Capgras' syndrome occurring in the puerperium, both with associated organic findings. Nilsson and Perris's case had enlarged ventricles and temporal lobe atrophy, while the patient reported by Foerstl ${ }^{8}$ had suffered a subarachnoid haemorrhage with consequent neurological deficit. Both woman misidentified their husbands and their children.

There have been two previous case reports of Capgras' syndrome with no obvious organic basis occurring in the puerperium. ${ }^{910}$ In both cases, the husbands as well as the newborn children were misidentified. In the case we report, there was also no obvious organic involvement but the child was the only misidentified person.

In a review of the dangerousness of the delusional misiden- 


\section{Did you know that Cipramil is the No.1 SSRI}

\section{in the following countries?}
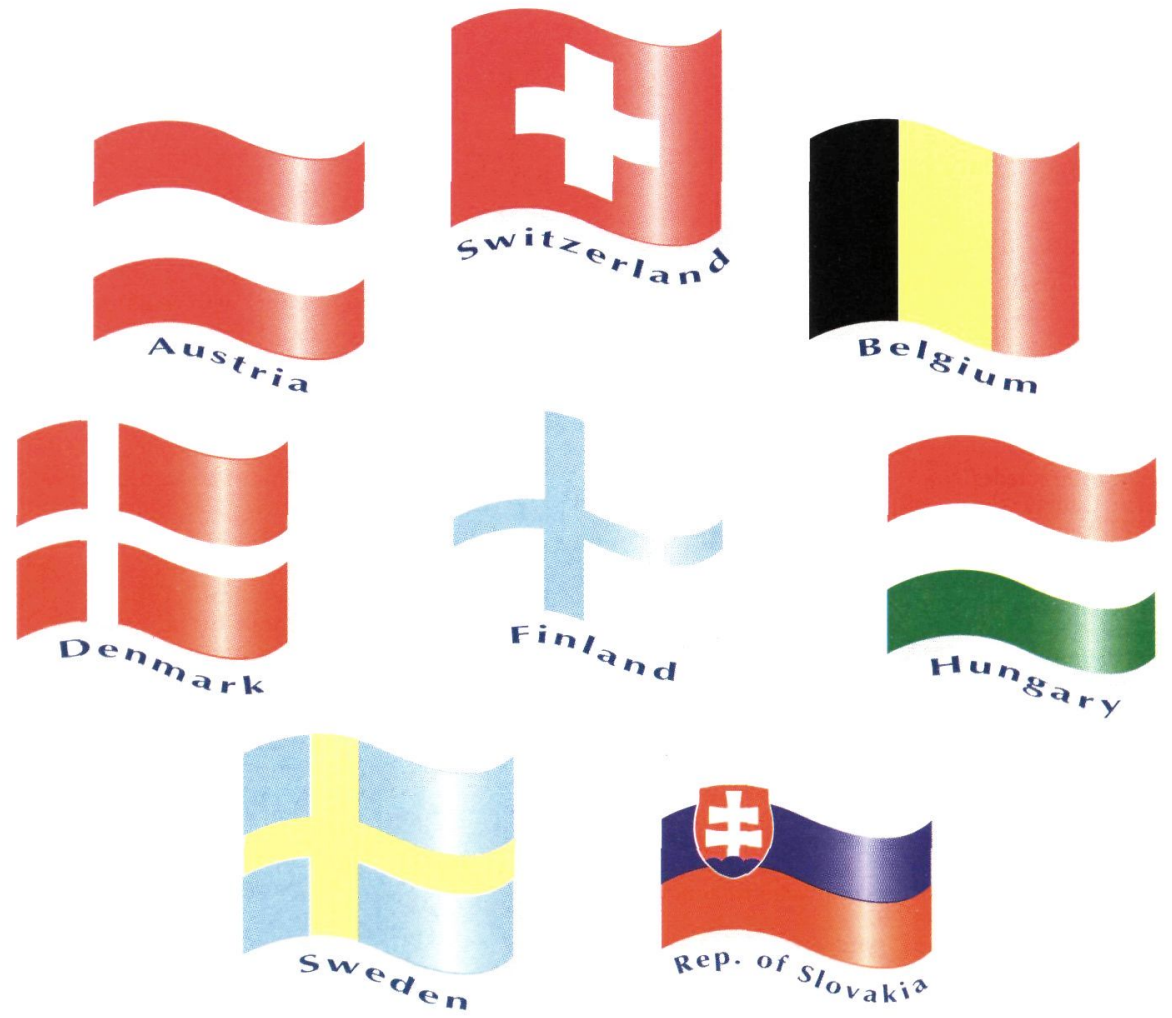

- The most selective SSRI available ${ }^{1,2}$

- Minimal drug interactions ${ }^{3}$

- Faster onset of action than fluoxetine ${ }^{4}$ ...it's no wonder why!
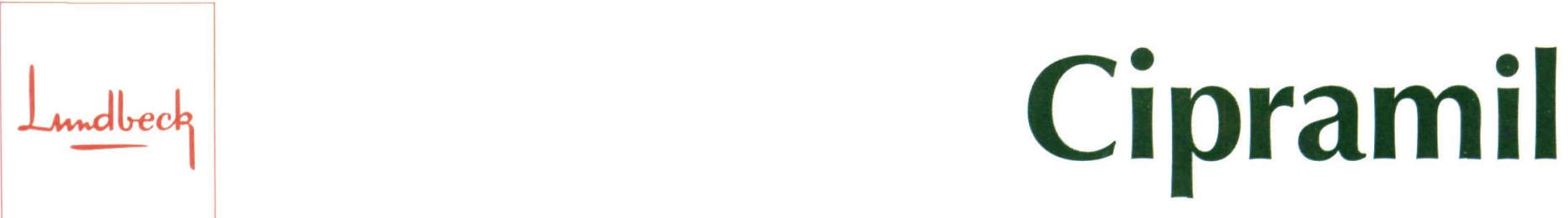

ABBREVIATED PRESCRIBING INFORMATION Presentation: 'Cipramil' tablets, each containing 20mg of citalopram as the hydrobromide. 28 (OP) $20 \mathrm{mg}$ tablets. Indications: Treatment of depressive lliness in the initial phase maximum initial phase and as maintenance against relapse/recurrence. Dosage: Adults. 20mg a day. Depending upon individual patient response, this may be increased in 20mg increments to a $40 \mathrm{mg}$ dependent. Tablets should not be chewed, and should be taken as a single oral daily dose, in the moming or evening without regard for food. Elaerty. 20mg a day increasing to a maximum of mild/moderate renal impaividual patient response. Children. Not recommended. Restrict dosage to lower end of range in hepatic impairment. Dosage adjustment not necessary in cases of citalopram. Pregnal impairment. No information available in severe renal impairment (creatinine clearance<20m//min). Contra-indications: Combined use of 5-HT agonists. Hypersensitiviting machinery. History oy and Lactation: Safety during human pregnancy and lactation has not been established. Use only if potential benefit outweighs possible risk. Precautions: Driving and operating Drug interactions: MAO inhibitors (see Precautions) Use lithium andythmias. Do not use with or within 14 days of MAO inhibitors; leave a seven day gap before starting Most commonly nausea, sweating, tremor, somnolence and dry methutions. Use lithium and tryptophan with caution. Routine monitoring or lithium levels need not be adjuste of grand mal convulsion, nausea, vomiting, sweating and hyperventilation. No specific antidote. Treatment is symptomatic and supportive. Early gastric lavage suggested. Legal Category: POM. Further information available on request. Product Authorisation holder: Lundbeck (Ireland) Limited, 5 Leopardstown Office Park, Foxrock, Dublin 18. PA number 776/1/2. 'Cipramil' is a trademark. 0 1995 Lundbeck (lreland) Limited. Date of preparation : November 1996. REFERENCES: 1. Hytell J. XXII Nordiske Psykiater Kongres Reykjavik. II August 1988, 11-21. 2. Eison AS et al, Psychopharmacology Bull 1990: 26(3) 311-315. 3. Sindrup

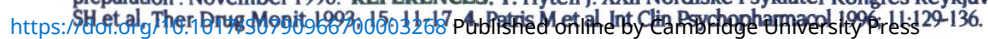


tification of children, Silva $e t$ a ${ }^{11}$ identified only one case where there were positive thoughts toward the misidentified child. The quality of the relationship toward the child is more commonly one of suspiciousness and hostility which can result in homicide. It was unusual, then, for $\mathrm{C}$ to say the misidentified baby was 'good' .

The onset of our patient's psychotic symptoms at 37 weeks, ie. prepartum, is worthy of comment. Brockington, Oates and Rose $^{12}$ reported four cases of prepartum psychosis and proposed criteria for accepting the proposition that puerperal psychosis can start before delivery. In their series, only one of the five prepartum episodes occurred during the first pregnancy. Glaze, Chapman and Murray ${ }^{13}$ reported two further cases of prepartum psychosis both during second pregnancies. In the case of $\mathrm{C}$, this was her first pregnancy carried to parturition. She meets four of Brockington $e t a l$ s five criteria failing ihe fifth only because she has to date had a single episode of illness.

The case is of interest primarily because of the differences in phenomenology to previously reported cases. It is of note also that the differences do not appear to have been negative prognostic indicators in that our patient responded as well to treatment as did the other cases.

\section{References}

1. Capgras J, Reboul-Lachaux J. Lillusion des 'sosies' dans un delire systematise chronique. Bulletin de la Societe Clinique de Medicine Mentale 1923; 2: 6-16. 2. Enoch MD, Trethowan WH. Uncommon Psychiatric Syndromes. 3rd ed. Oxford: Butterworth-Heinemann, 1991.

3. Cox JL. In: Companion to Psychiatric studies. Kendell RE, Zealley AK eds. 5 th ed. Edinburgh: Churchill Livingstone, 1993.

4. World Health Organisation: The ICD-10 classification of mental and behavioural disorders: clinical descriptions and diagnostic guidelines. Geneva: World Health Organisation, 1992.

5. American Psychiatric Association: Diagnostic and statistical manual of mental disorders. 4th ed. Washington DC: American Psychiatric Association, 1994.

6. O'Sullivan D, Dean C. The Fregoli syndrome and puerperal psychosis. Br J Psychiatry 1991; 159: 274-7.

7. Nilsson R, Perris C. The Capgras syndrome: a case report. Acta Psychiatr Scand 1971; 221(suppl): 53-8.

8. Foerstl H. Capgras' delusion: an example of coalescent psychodynamic and organic factors. Compr Psychiatry 1990; 31(5): 447-9.

9. Cohn CK, Rosenblatt S, Faillace LA. Capgras' syndrome presenting as postpartum psychosis. South Med J 1977; $70(8): 942$.

10. De Leo D, Galligioni S, Magni G. A case of Capgras' delusion presenting as a post partum psychosis. J Clin Psychiatry 1985; 46: 242-3.

1 l. Silva JA, Sharma KK, Leong GB, Weinstock R. Dangerousness of the delusional misidentification of children. J Forensic Sci 1992; 37(3): 830-8.

12. Brockington IF, Oates M, Rose G. Prepartum psychosis. J Affective Disorders 1990; $19: 31-.5$

13 Glaze R, Chapman G, Murray D. Recurrence of puerperal psychosis during late pregnancy. Br J Psychiatry 1991; 159: 567-9.

Dev A Ratan MRCPsych, Consultant Psychiatrist, Leicestershire Mental Health Service NHS Trust,

Trevor Friedman MRCPsych, Consultant Psychiatrist,

Leicestershire Mental Health Service NHS Trust, Brandon Mental Health Unit, Gwendolen Road, Leicester LES 4PW, England.

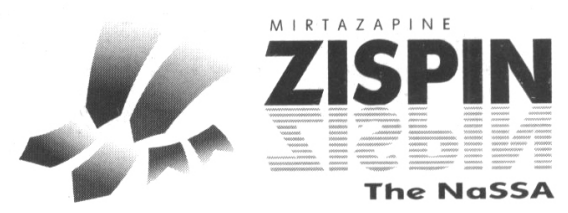

ZISPIN Prescribing Information

Presentation Blister strips of 28 tablets each containing $30 \mathrm{mg}$ of mirtazapine. Uses Episode of major depression. Dosage and administration The tablets should be taken orally, if necessary with fluid, and swallowed without chewing. Adults and elderly The effective daily dose is usually between 15 and $45 \mathrm{mg}$. Children Not recommended. The clearance of mirtazapine may be decreased in patients with renal or hepatic insufficiency. Zispin is suitable for once-a-day administration, preferably as a single night-time dose. Treatment should be continued until the patient has completely symptom-free for 4-6 months. Contraindications Hypersensitivity to mirtazapine. Precautions and warnings Bone marrow depression, usually presenting as granulocytopenia or agranulocylosis, has been reported during treatment with most antidepressants. The physician should be alert to symptoms like fever, sore throat, stomatitis or other signs of infection; when such symptoms occur, treatment should be stopped and blood counts taken. Careful dosing os well as regular and close monitoring is necessary in patients with: epilepsy and organic brain syndrome; hepatic or renal insufficiency, cardiac disease; low blood pressure. Like with other antidepressants care should be taken in patients with: micturition disturbances like prostate hypertrophy, acute narrow-angle glaucoma and increased intra-ocular pressure and diabetes mellitus. Treatment should be discontinued if jaundice occurs. Moreover, like with other antidepressants, the following should be token into account: worsening of psychotic symptoms can occur when antidepressants are administered to patients with schizophrenia or other psychotic disturbances; when the depressive phose of manic-depressive psychosis is being treated, it can transform into the manic phase. Zispin has sedative properties and may impair concentration and alertness. Interactions In vitro data suggest that clinically significant interactions are unlikely with mirtazapine. Mirtazapine may potentiate the central nervous dampening action of alcohol; patients should therefore be advised to avoid alcohol during treatment with Zispin; Zispin should not be administered concomitantly with MAO inhibitors or within two weeks of cessation of therapy with these agents; Mirtazapine may potentiate the sedative effects of benzodiazepines. Pregnancy and lactation The safety of Zispin in human pregnancy has not been established. Use during pregnancy is not recommended. Women of child bearing potential should employ an adequate method of contraception. Use in nursing mothers is not recommended. Adverse reactions The following adverse effects have been reported: Common: Increase in appelite and weight goin. Drowsiness/sedation, generally occurring during the first few weeks of treatment. (N.B. dose reduction generally does not lead to less sedation but can jeopardize antidepressant efficacy). Rare: (Orthostatic) hypotension. Mania. Convulsions (insults), tremor, myoclonus. Oedema and accompanying weight gain. Acute bone marrow depression (eosinophilia, granulocytopenia, agranulocyrosis, aplastic anemia and thrombocytopenia). Elevations in serum transaminase activities. Exanthema. Overdosage Toxicity studies in animals suggest that clinically relevant cardiotoxic effects will not occur after overdosing with Zispin. Experience in clinical trials and from the market has shown that no serious adverse effects have been associated with Zispin in overdose. Symptoms of acute overdosage are confined to prolonged sedation. Cases of overdose should be treated by gastric lavage with appropriate symptomatic and supportive therapy for vital functions. Marketing authorisation number PA 261/43/2. Legal categony Prescription Medicine.

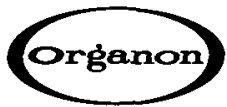

Further information is available from: Organon Laboratories Limited,

Cambridge Science Park, Milion Road, Cambridge, CB4 4FL, England.

Telephone: 01223423445 .

Distributor: United Drug PIc, Belgard Road, Tallaght, Dublin 24, Eire. 